\title{
LA-UR-17-27209
}

Approved for public release; distribution is unlimited.

Title:

Author(s):

Intended for:

Issued:
Space Focus Lead Report

Reeves, Geoffrey D.

Review Panel Presentation 
Disclaimer:

Los Alamos National Laboratory, an affirmative action/equal opportunity employer, is operated by the Los Alamos National Security, LLC for the National Nuclear Security Administration of the U.S. Department of Energy under contract DE-AC52-06NA25396. By approving this article, the publisher recognizes that the U.S. Government retains nonexclusive, royalty-free license to publish or reproduce the published form of this contribution, or to allow others to do so, for U.S. Government purposes. Los Alamos National Laboratory requests that the publisher identify this article as work performed under the auspices of the U.S. Department of Energy. Los Alamos National Laboratory strongly supports academic freedom and a researcher's right to publish; as an institution, however, the Laboratory does not endorse the viewpoint of a publication or guarantee its technical correctness. 


\title{
CSES: Center for Space and Earth Science
}

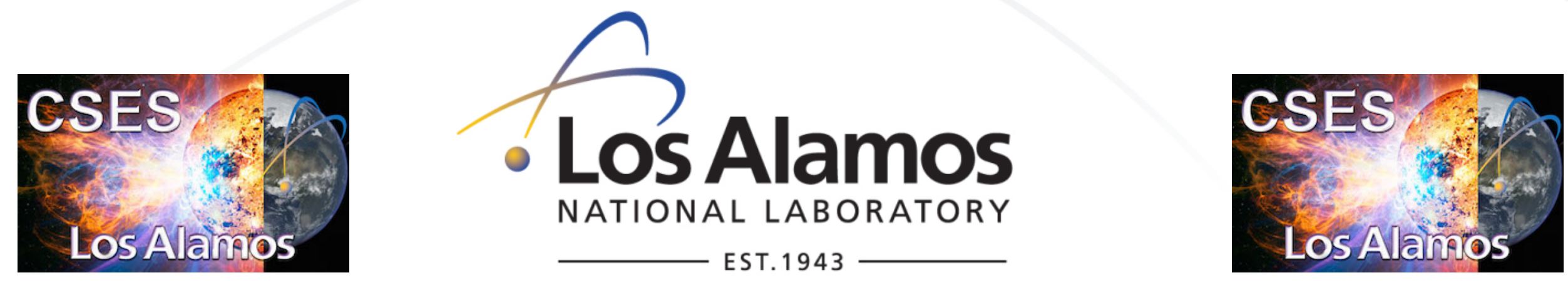

\section{Space Focus Lead Report}

\author{
Geoff Reeves \\ July $19^{\text {th }}, 2017$
}




\section{Topics}

- Space Focus Team

- FY 16 Focused Science Topics

- FY16-17 Student Projects

- FY16-17 Large Project

- FY16-17 PostDoc Project

- FY16-17 Emerging Ideas PD

- FY16-17 Emerging Ideas R\&D

- FY16 $6^{\text {th }}$ Space Weather Summer School

- Two New Space Seminar Series 


\section{Space Focus Team}

The Space Focus team is tasked with the definition of the Space Focused Science Topics, and with the review and ranking of the CSES proposals received in all the program areas. This is achieved by dedicated meetings or a series of informal discussions and/or e-mail reviews.

- Geoff Reeves, Space Focus Lead

- External team members picked from current and former EAC members + other willing volunteers based on availability etc.

- Internal reviewers picked according to expertise and lack of conflict (sometimes difficult)

- Advice \& direction welcome from all quarters.

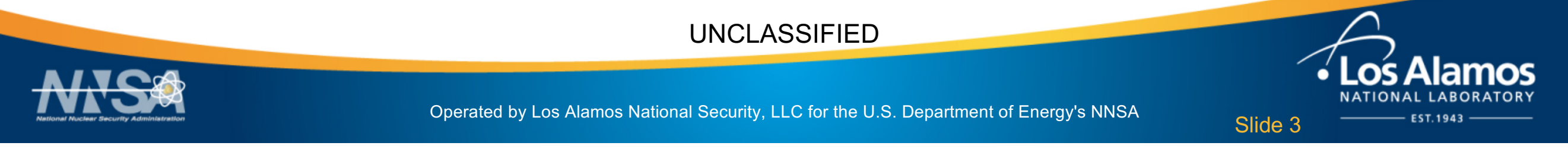




\section{FY16 Focused Science Topics: First science/program focus = Agile Space}

- The terms responsive space and agile space refer to technologies and scientific understanding that enable rapid and innovative execution of space missions or that helps operators anticipate and mitigate threats to their space assets. Space is increasingly important for national and global security. Therefore there is an increasing need to understand and predict the space environment, to anticipate and respond to changing threats in space, and to rapidly deploy space systems tailored to meet evolving national security needs. 


\section{FY16 Focused Science Topics: Agile Space: Specific Topics Solicited}

- Novel techniques. Understand complex, heterogenous observations from or about space.

- Cube/Nano-sats. Research utilizing cubesats, nano-sats, and satellite constellations or research enabling design of such missions.

- Instruments/Measurements. Development of novel instrument and/or measurement techniques for space science or of systems that help characterize objects in space

- Modeling. Development of numerical models that predict and help mitigate threats in space.

- Bonus: proposals that exploit LANL resources

- LANL satellite experiments

- LANL satellite data

- LANL space science computer simulation codes, and algorithms. 


\section{FY16-17 Space Projects Student Projects}

- Laboratory Validation of Electron Beam Emission Mediated by a Plasma Contractor, Gian Luca Delzanno, T-5, University of Michigan

- In support of risk mitigation for planned NASA Mission Concept "Connex" - see science talk by Gian Luca this afternoon

- The Effect of ULF Wave Azimuthal Structure on the outer Radiation Belt, Geoff Reeves (LANL), Mike Hartinger (Virginia Tech)

- Started as a Postdoc project at University of Michigan for Mike Hartinger, with Reiner Friedel as LANL PI

- On becoming Center Lead project transitioned to Geoff Reeves

- Hartinger Moved to Virginia Tech, CSES insisted that the project is for a Student, who is now engaged

- Hartinger Visiting at LANL each year, 2 days this semester. He and his student Taikara Peek visiting for 2 days in August. Several meetings with Hartinger at meetings (AGU, SWG) to discuss project 


\section{UVA Student Project}

Radiation belt response to large scale, monochromatic ULF waves: LANL-GEO observations (GEM presentation)

- ULF wave interactions are often treated as diffusive: transport timescales on order of days

- Non-diffusive transport can occur on much more rapid timescales: rapid enhancements/depletions in electron fluxes on timescales $<1$ hour

- Hard to predict non-diffusive behavior

- Goal: observational constraints on non-diffusive behavior based on measured wave properties (frequency, amplitude, mnumber, local time, propagation direction)
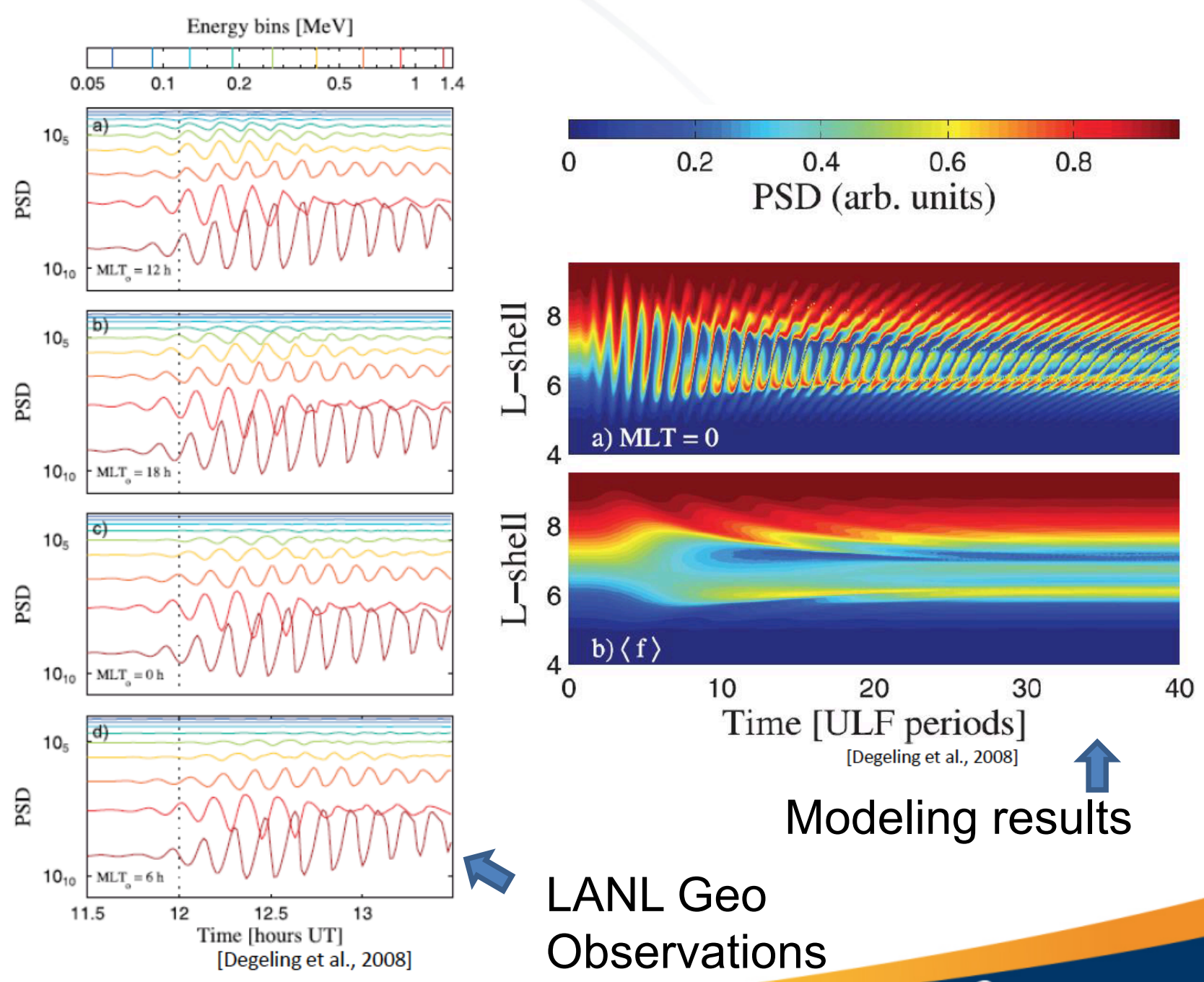

LANL Geo Modeling results

UNCLASSIFIED 


\section{UVA Student Project}

Radiation belt response to large scale, monochromatic ULF waves: LANL-GEO observations (GEM Presentaion)

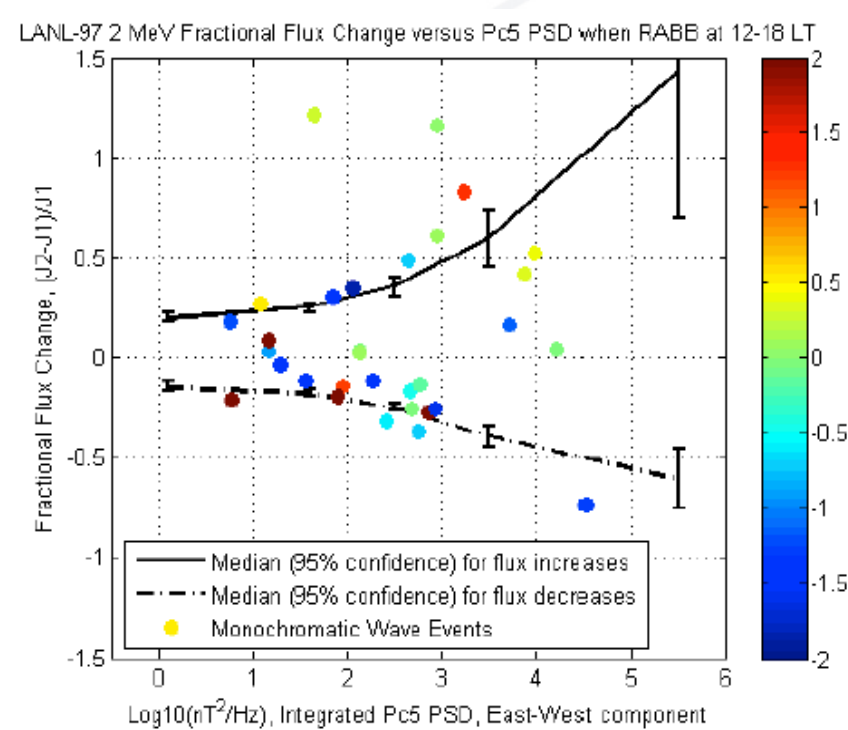

$\log 10\left(\mathrm{nT}^{2} / \mathrm{Hz}\right)$, Integrated Pc5 PSD, East-West component

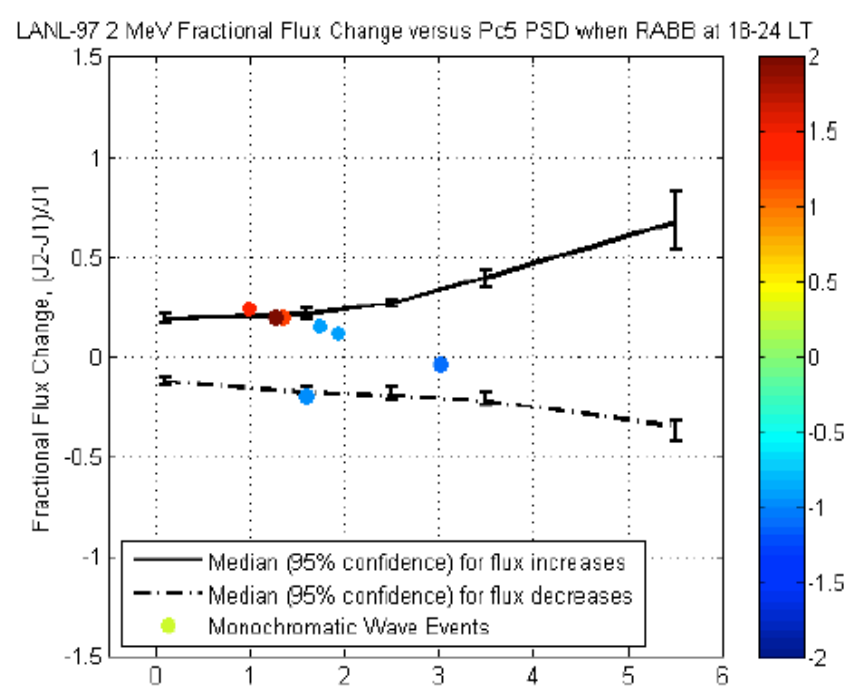

$\log 10\left(\mathrm{nT}^{2} / \mathrm{Hz}\right)$, Integrated PC5 PSD, East-West component
Percent change in flux as a function of ULF wave power shows measurable trends.

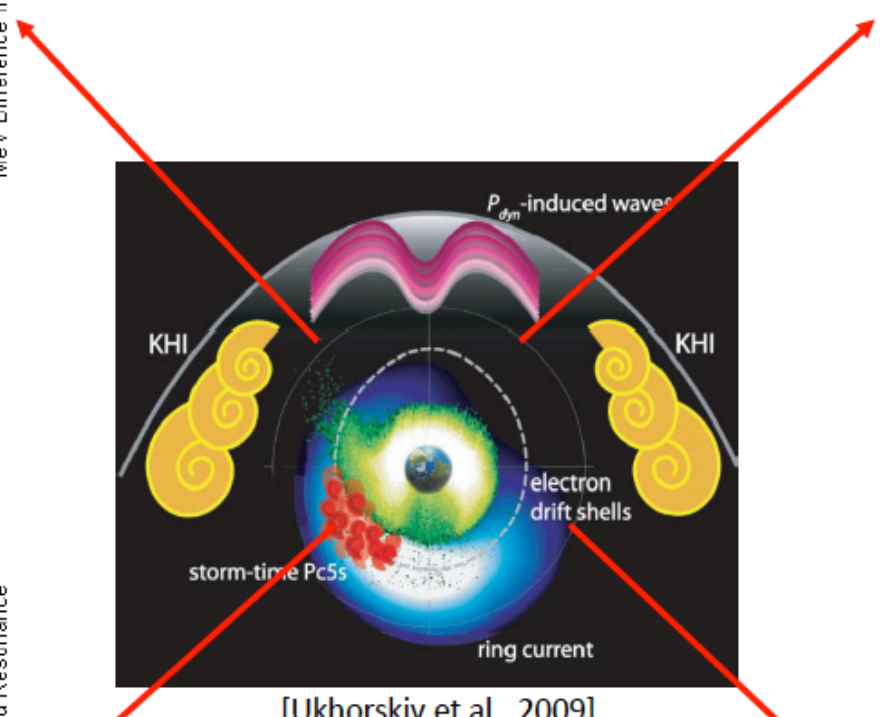
dJ shown for monochromatic wave events, color coded based on predicted resonant energy (based on m-number, frequency

- These waves can produce more rapid changes in flux when wave velocity matches local electron drift velocity
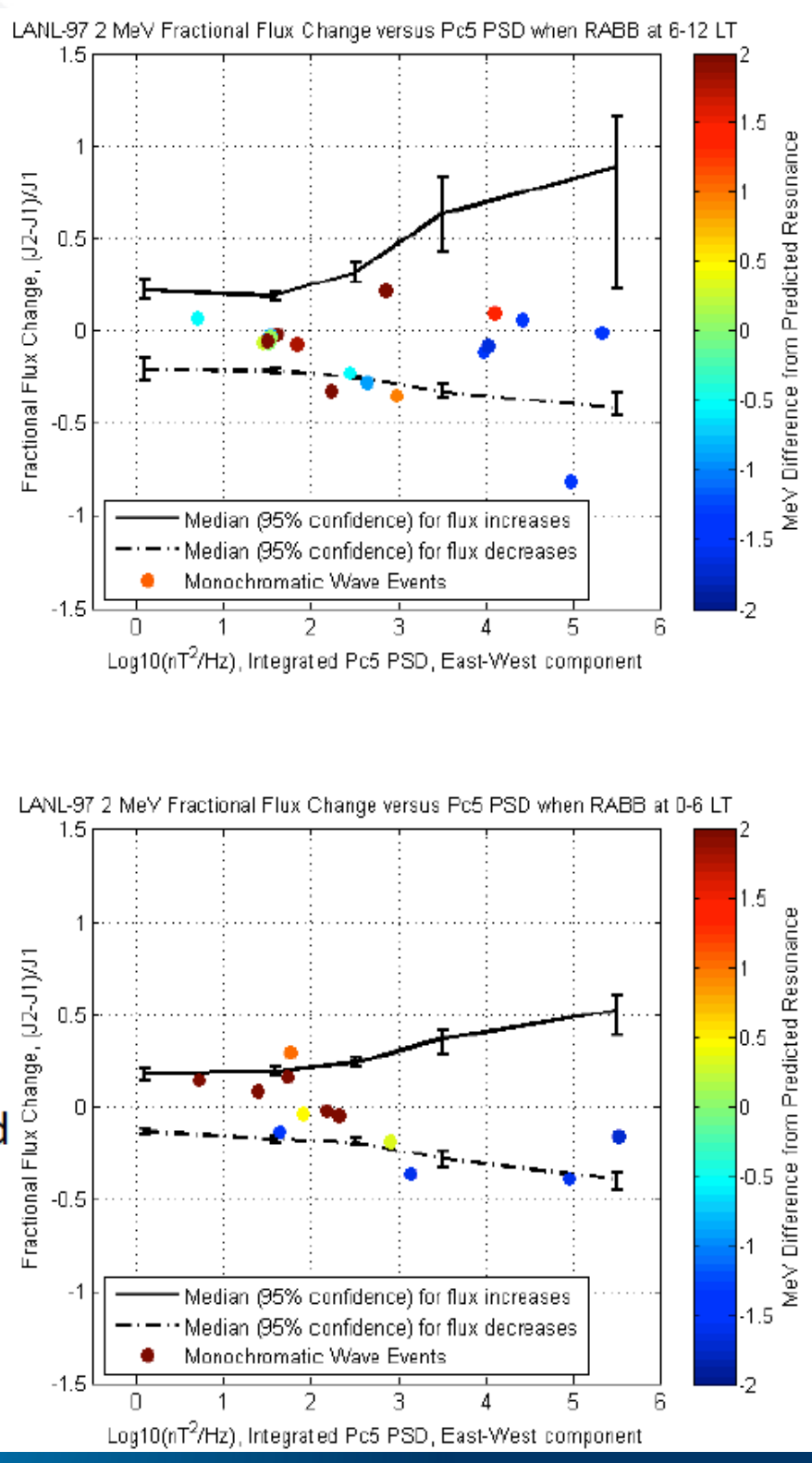


\section{FY17 Space Projects Student Projects}

- Kinetic Electron Dynamics of Asymmetric Reconnection, Bill Daughton, XTD-PRI

- FY17 project, early on, no result yet to present 


\section{FY 16-17 Large Space Project Grandfathered form IGPPS}

- Listen to the Canary: Understanding and Utilizing a Storm Precursor in Low-Earth-Orbit, Yue Chen, ISR-1

- 100k project, a large project experiment aimed at junior staff

- 2 Publications and several conference contributions

- Regular technical seminars

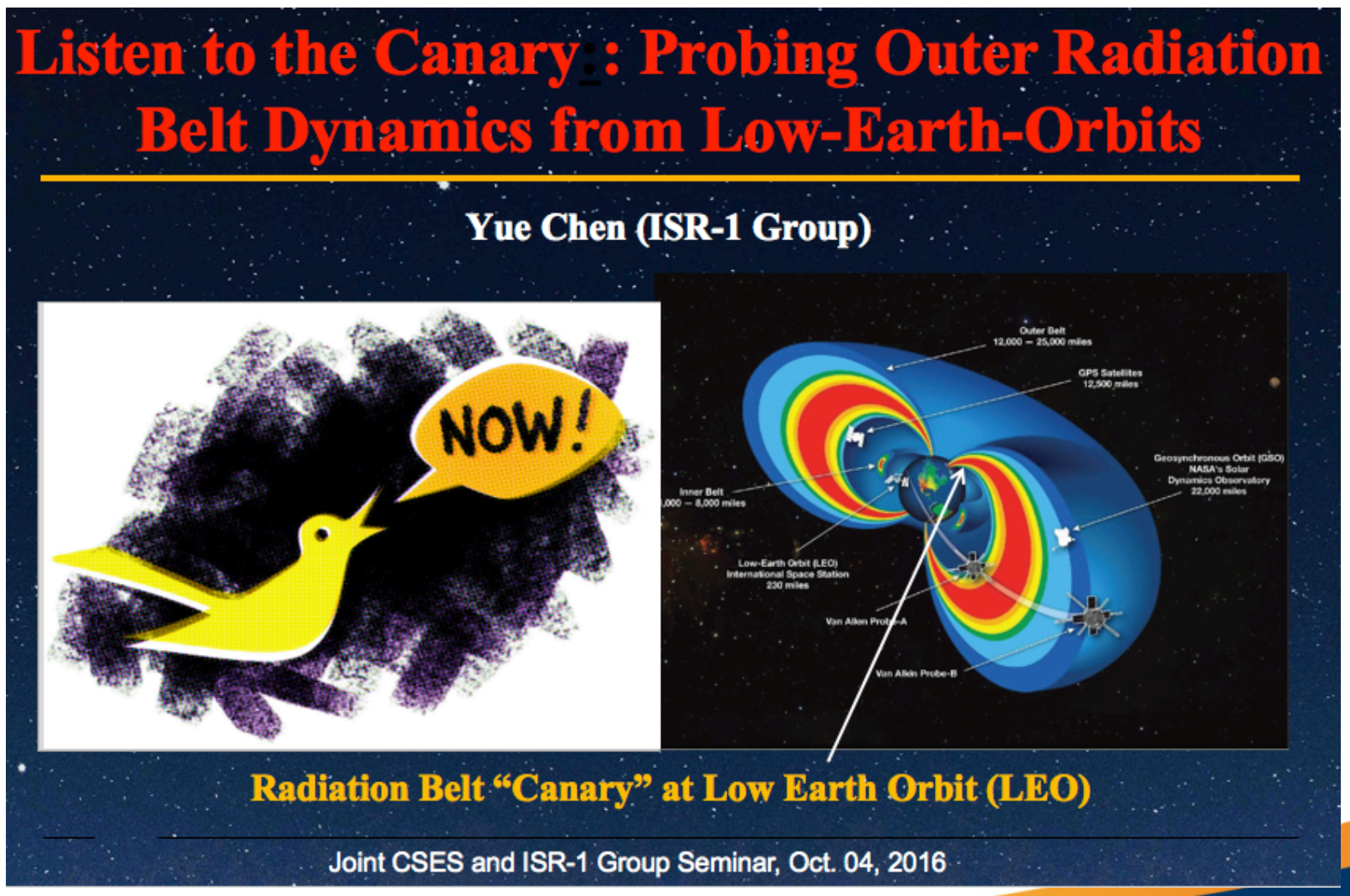

UNCLASSIFIED 


\section{Large Project Seminar}

Listen to the Canary: Probing Outer Radiation Belt Dynamics from Low-Earth-Orbits

Inputs needed by radiation belt models:

- Chorus, hiss, EMIC and MS waves

- ULF waves (radial diffusion)

- Seed population

- Background plasma condition

- Background B/E field and moving magnetopause

$\square$ Outer-belt modeling challenges:

- Type I: Parameters that are not complete from sparse in-situ measurements (e.g., chorus distributions',

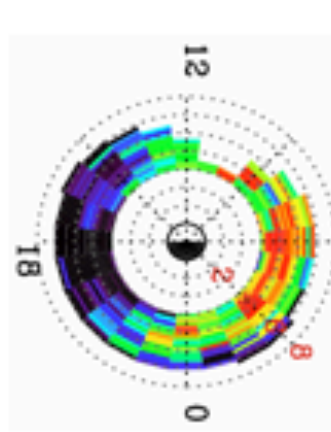

$$
\text { द्व }
$$

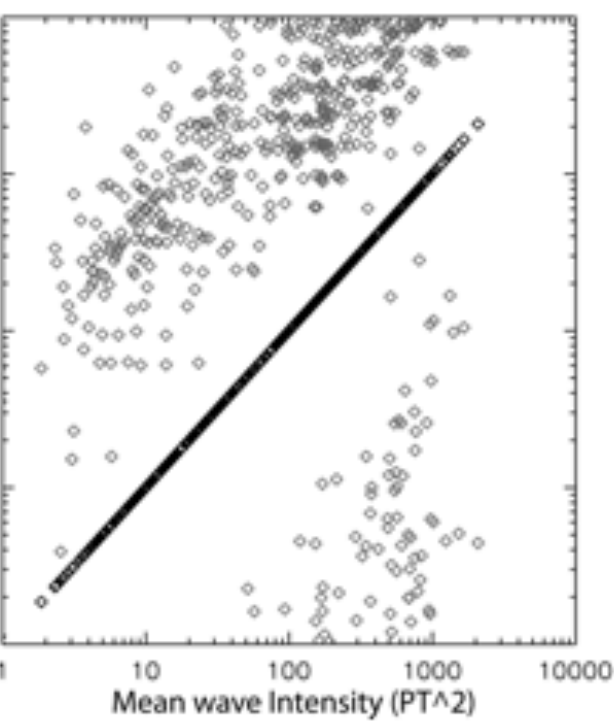

Chen et al., 2014 GRL

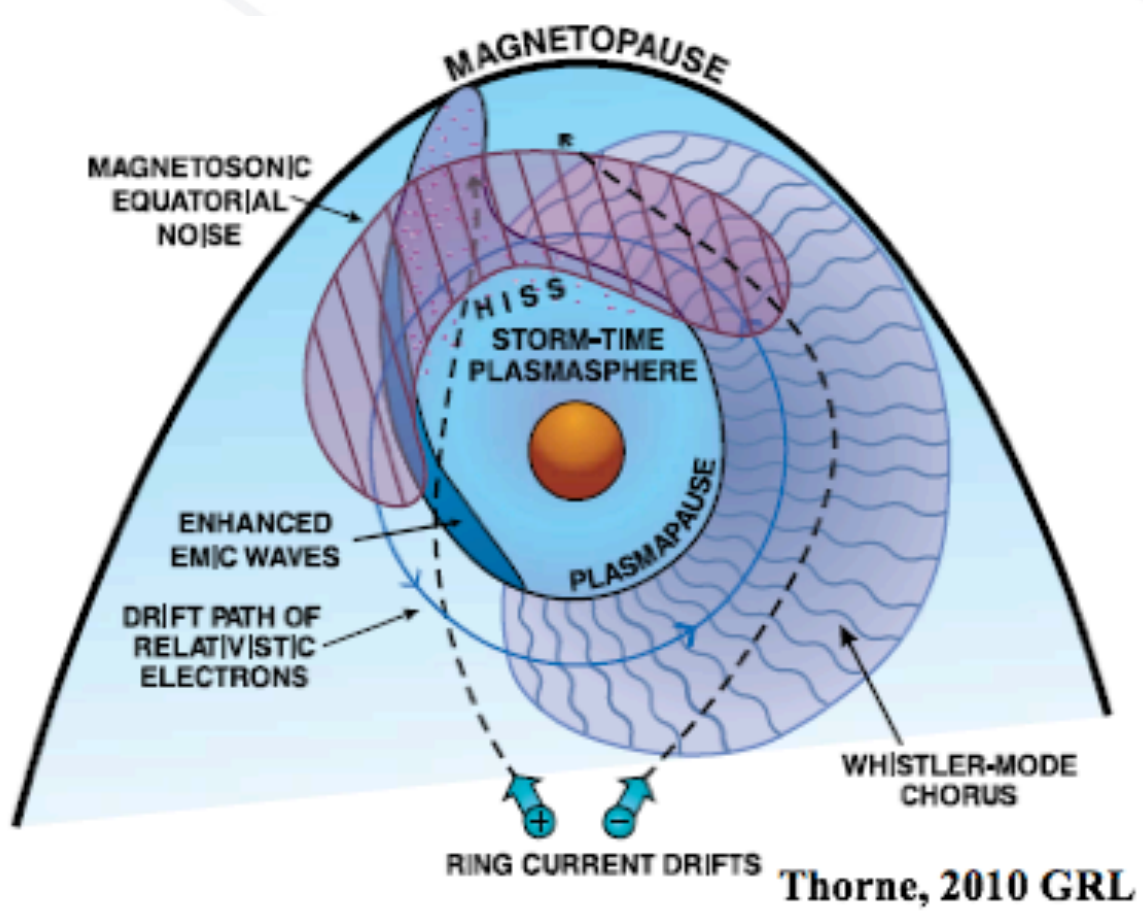

Type II:

- Even in-situ measurements will be gone in postRBSP era (e.g., seed electron population).

- Undetermined physics (e.g., MS wave effects)

Solution: Application-oriented Data Analysis

- Observational correlation, application, verification and validation, and physics 


\section{Large Project Seminar}

Listen to the Canary: Probing Outer Radiation Belt Dynamics from Low-Earth-Orbits

Conclusion: LEO observations of $100 \mathrm{~s} \mathrm{KeV}$ electrons (POES E2, E3 and P6) can be directly used for remote sensing and predicting $\mathrm{MeV}$ electrons in the outer belt.

$\square$ Observations: Significant one-to-one temporal relation between trapped relativistic electrons ( $1 \mathrm{MeV}$ in our case) observed by Van Allen Probes and precipitating $\sim 100 \mathrm{~s} \mathrm{keV}$ electrons by NOAA POES at LEO (Cross-energy cross-pitch-angle coherence).

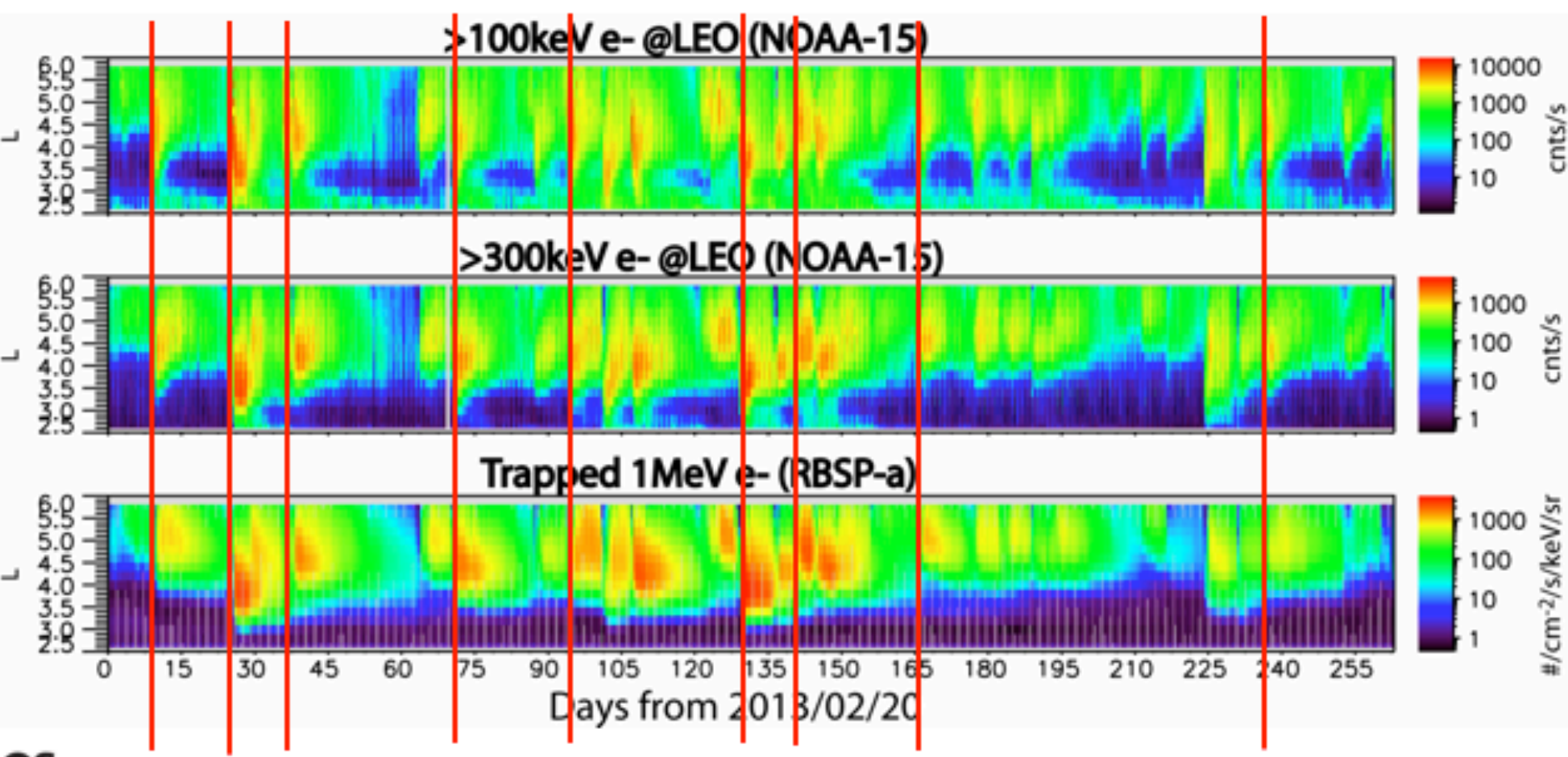




\section{Large Project Seminar}

Listen to the Canary: Probing Outer Radiation Belt Dynamics from

Low-Earth-Orbits

High correlation coefficient values exist for $L$ shells within $3.5-5.0$ between the 5-hourly binned POES E2 and E3 and RBSP data over long term

- Right panels for data over 2012.12 - 2013.12

- Similar correlation is found for 2014 data

- Similar prediction filter performance is expectable for other L-shells
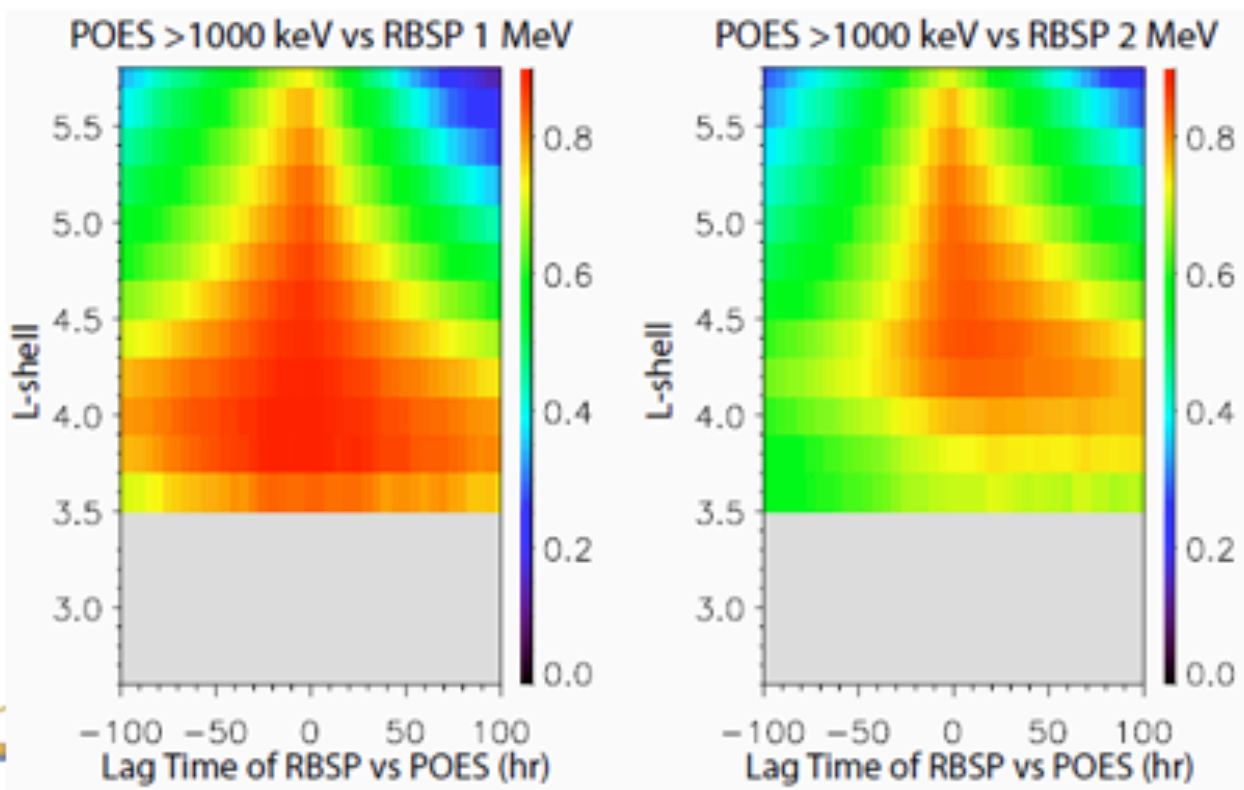
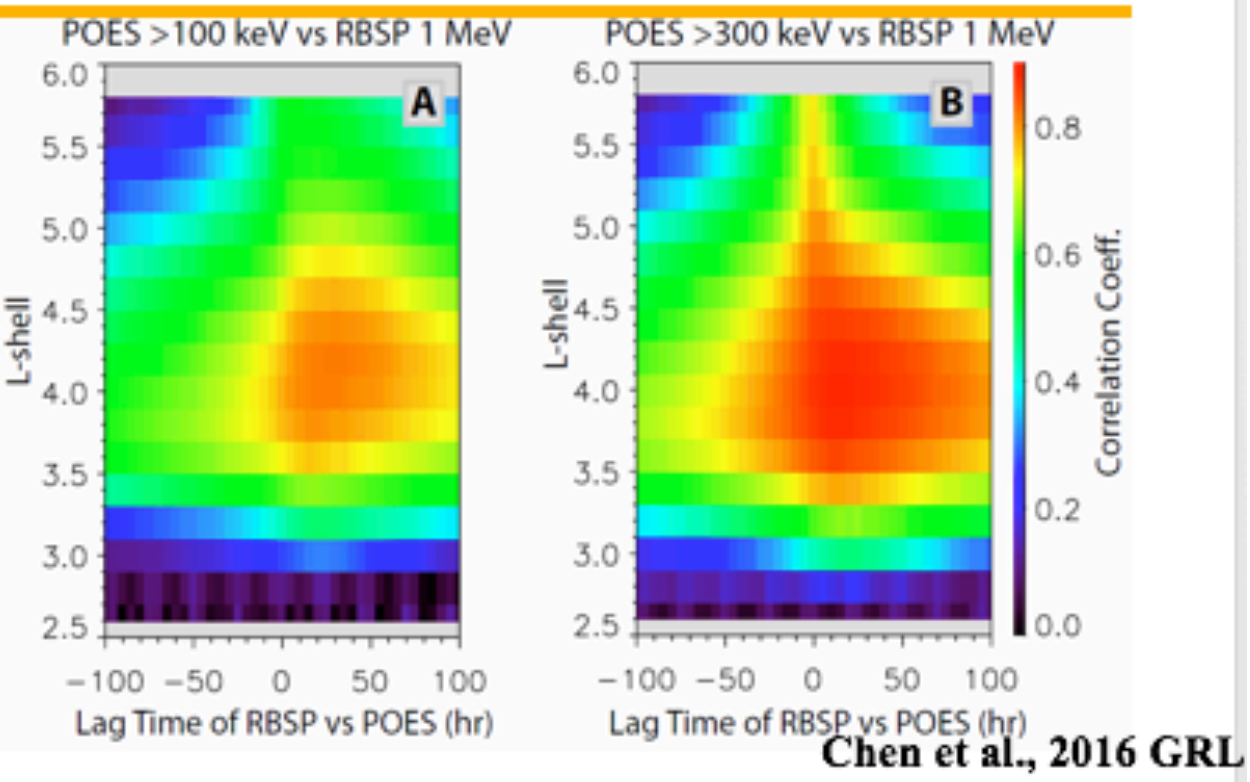

$\square$ The cross-energy cross-pitch-angle coherence extensively and persistently exists for a range of $\mathrm{L}$-shells, multiple energies between precipitating $100 \mathrm{~s} \mathrm{keV}$ and trapped $\mathrm{MeV}$ electrons.

- Exists between POES P6 and trapped 1 and $2 \mathrm{MeV}$ electrons

- Multiple predictive points for nowcasting and forecasting $\mathrm{MeV}$ electrons for the whole outer belt 


\section{FY16-17 Space Project PostDoc Projects}

- Electron Acoustic Double Layers in Earth's Magnetopshere, LANL PI Misa Cowee, ISR-1

- Sean Fu now Researcher at NMC Space Group under RBSP Project

- 1 year, 3 months support, 1 paper 3 conference publications

- Enabling Heliospheric Radiography: Proof of Concept for a Transformation Cosmic Ray Imager, Herb Funsten, ISR-1

- Project Aborted half way, funding returned. Lab experiments of detector with radioactive source turned out to be not feasible at LANL.

- Postdoc at LANL on other funding, will try for outside facility, new project in FY18 


\section{FY16-17 Emerging Ideas Program Development}

- Assessing substorm prediction capabilities and feasibility of proposed methodologies, Steve Morely, ISR-1

- Teaming with University of Michigan for NASA HSR and Large NSF GEM proposal, teaming visits, not yet submitted

- Artificial Radiation Belts from Lower-Altitude HANEs: How Do We Model the Transition to the Collisional Regime?

- OUO only, Export Controlled Project report submitted (LA-CP-17-20007)

- Cannot show at meeting

- Most Space PD proposal done with partnered funding, see CSES/NASA report tomorrow. 


\section{FY16-17 Emerging Ideas}

Research and Development

- Feasibility Study of Using a Pulsed Space-Based Electron Accelerator for Radiation Belt Remediation, Bruce Carsten, ADE

- Work led to LDRD-ER proposal. Not selected as "too programmatic" - to be resubmitted as an LDRD-DR, reserve proposal in the works for FY18

- RAM-SCB simulations of effect of PADs on Ring current pressure, Vania Jordanova, ISR-1

- Supported an aspect of her project not covered in her LDRD-DR project, 15K

- Led to one publication and a conference talk

- Elpasolite Planetary Ice and Composition Spectrometer (EPICS), Laura Stonehill, GS-IET

- Initial lab based instrument development work, led to a submitted large mission proposal for JAXA MMX 


\section{FY16-17 Emerging Ideas}

Research and Development

- DREAM Capability Demonstration Utilizing Van Allen Probe Space Environment Data, Andrew Walker, ISR-1

- Real time Dream installed at NOAA SwPC Boulder and NASA CCMC

- Part of joint KSWC / NOAA / LANL work

- $\quad 75 \%$ done, some funding returned, RBSP Beacon work deferred to FY18

- IMAP-Hi The High Energy Neutral Atom Imager for the Interstellar Mapping and Acceleration Probe (IMAP), Herb Funsten, ISR-1

- IMAP AO expected June (now August?)

- Instrument lab development support

- Proposal sensitive info, not shown here 


\section{FY16 $6^{\text {th }}$ Space Weather Summer School}

- 8 students participated (36\% acceptance rate)

- $\quad$ US citizens $=1, \mathrm{FNs}=7$ (7 countries represented)

- US universities $=3$, Foreign universities $=5$

- male $=5$, female $=3$

- Total applications: 22

- US citizens $=2$, FNs $=20$ (12 countries represented)

- US universities $=8$, Foreign universities $=14$

- male $=16$, female $=6$

- Kateryna Yakymenko, August 2017 Postdoc in T-5

" Her partner Oleksandr Koshkarov "in queue" for 2018, still finishing his $\mathrm{PhD}$.

- FY 2018 School in planning stages (Jesse Woodroffe) 


\section{Two New Space Seminar Series FY 2017}

- Advances in Space Research, Fan Guo,T-2 and Jesse Woodroffe, ISR-1

- June 8, Antti Pulkkinen, GSFC

- Mary Hudson, Dartmouth College

- July 19: Josh Rigler, United States Geological Survey

- August 29: Delores Knipp, University of Colorado, Space Weather journal editor

- September 6: Emma Spanswick, University of Calgary

- Planetary Science Lecture Series, Nina Lanza, ISR-2

- August 2016: Nina Lanza (LANL)

- Oct. 27, 2016: Ann Ollila (LANL)

- Nov. 14, 2016: Craig Hardgrove (ASU)

- May 8, 2017: Woody Fischer (Caltech)

- August TBD (working on it now!): Tanya Harrison (ASU) 